\section{Interrelations of Serum Protein Fractions in Normal Humans}

RECENT advances in the study of protein-protein interactions ${ }^{1}$, including the haptoglobin-hæmoglobin ${ }^{2}$ and protamine-fibrinogen ${ }^{3}$ complexes, have stimulated interest in serum protein abnormalities such as macroglobulin aggregation ${ }^{4}$. Although the serum proteins frequently undergo significant alterations with the onset of disease and yield characteristic patterns on electrophoretic separation, little is known about their interdependence in the healthy state. The present report describes an electrophoretic examination of interrelations between protein fractions in the course of variations within the normal human range.

Blood was obtained from 100 healthy persons between the ages of sixteen and seventy-two. There were equal numbers of males and females. Serum proteins were separated by cellulose acetate electrophoresis and stained with lissamine green. The dyed fractions were eluted, and the concentrations of albumin and $\alpha_{1^{-}}, \alpha_{2^{-}}, \beta$-, and $\gamma$-globulins then calculated by comparing the quantity of eluted dye with the known dye uptakes of standard preparations. Since for each sex the means between the corresponding fractions were not significantly different, the two groups were combined. Table 1 summarizes the results.

Table 1. Means and Standard Deviations of Serum Protein Fractions of 100 Normal Phrsons

\begin{tabular}{|c|c|cccc|}
\hline & Albumin & \multicolumn{4}{|c|}{ Globulins } \\
& $\alpha_{1}$ & $\alpha_{2}$ & $\beta$ & $\gamma$ \\
\hline Mean (gm./100 ml.) & 4.07 & 0.30 & 0.78 & 0.92 & $1 \cdot 29$ \\
\pm Standard deviation & 0.37 & 0.04 & 0.11 & 0.12 & 0.23 \\
\hline
\end{tabular}

The five fractions were approximately normally distributed and, using standard statistical procedures, the partial correlation coefficients of the ten possible pairs were determined. Table 2 indicates that the most significant values were obtained for the pairs derived from the $\alpha_{1^{-}}, \alpha_{2}-$, and $\beta$-globulins. It is noteworthy that the least significant values are those of pairs involving $\gamma$-globulin of reticulo-endothelial origin with the other proteins of hepatic origin.

Table 2. Partial Correlation Coefficients of Normal Serum Protein fractions

\begin{tabular}{|l|cccc|}
\hline & \multicolumn{4}{|c|}{ Globulins } \\
\hline Albumin & $\alpha_{1}$ & $\alpha_{2}$ & $\beta$ & \multicolumn{1}{c|}{$\gamma$} \\
\hline$\alpha_{1}$-Globulin & -0.183 & -0.145 & 0.210 & 0.031 \\
$\alpha_{2}$-Globulin & & 0.987 & 0.317 & 0.067 \\
$\beta$-Globulin & & & 0.247 & -0.046 \\
& & & & 0.029 \\
\hline
\end{tabular}

The virtually perfect correlation between $\alpha_{1}$ - and $\alpha_{2}$-globulins is explicable in terms of similarity of constitution. Both fractions comprise glycoproteins and lipoproteins, and have sedimentation rates close to 3 Svedberg units ${ }^{5}$. Similarly, the $\alpha_{1}$-globulin$\beta$-globulin correlation can be considered to result from the lipid moiety common to each; both sediment at $5 S^{5}$. The lower correlation between $\alpha_{2}$ - and $\beta$-globulins may be attributable to the glycoproteins and lipoproteins contained in each. Both sediment in the ultracentrifuge at 7 and $12 \mathrm{~S}^{6}$.

The most significant negative correlation was found for albumin $-\alpha_{1}$-globulin. In this connexion Schultze? has noted that some $\alpha_{1}$-globulin is carried by albumin under paper electrophoretic conditions, while Tata ${ }^{8}$ has demonstrated the existence of a prealbumin$\alpha$-globulin complex. Of interest is the present finding that the albumin-- $\gamma$-globulin relation is not inverse as it frequently is in disease. It is certain that the behaviour of some protein fractions as dependent variables is, like their distribution ${ }^{9}$, governed by experimental conditions.

\section{J. BrackenRIDGE}

Biochemistry Department,

Royal Perth Hospital, Perth,

Western Australia.

1 Waugh, D. F., Adv. Protein Chem., 9, 325 (1954).

2 Jayle, M. F., Bull. Soc. Chim. Biol. (Paris), 21, 14 (1939).

a Mylon, E., Winternitz, M. C., and Sütö-Nagy, G. J., J. Biol. Chem., 143, 21 (1942).

${ }_{4}^{4}$ Deutsch, H. F., and Morton, J. I., Science, 125, 600 (1957).

5 Brattsten, I., Ark. Kemi, 8, 347 (1956).

6 Wallenius, G., Trautman, R., Kunkel, H. G., and Franklin, E. C.,

; Schultze, H. E., Clin. Chim. Acta, 3, 24 (1958).

8 Tata, J. R., Nature, 183, 877 (1959).

9 Armstrong, S. H., Budka, M. J. E., and Morrison, K. C., J. Amer. Chem. Soc., 69, 416 (1947).

\section{PATHOLOGY}

\section{A New Factor in the Use of Antibiotics}

New clinical problems have arisen from the inten. sive use of antibiotics during the past twenty years. During this time, several aspects of those problems have been studied in an attempt to elucidate the various mechanisms related to the sensibility, resistance and dependence of micro-organisms as well to the mode of action of antibiotics.

When observations are made, not in vitro, but in host organisms, the interpretation of the phenomenon becomes more confused due to the many variables taking part in the problem and to the effect of antimicrobial activity added to humoral defensive responses of the host against the pathogenic agent. In these responses, both the drug effect breaking down the equilibrium of normal phagocytic activity and the formation of antimicrobial antibodies are often found.

Irregularities in the activity of antibiotic suspensions have been observed by us between serum of patients having different levels of antibiotic and their specific antimicrobial activity, as well as when looking at the behaviour of bacteria against the antibiotics or their associations. Certain irregularities were found in associations of antibioties of known in vitro bactericidal activity when this activity was greatly reduced in vivo, during treatment of the parasitized organism. In spite of adequate dosing, sera of various patients with analogous symptoms and under the same treatment showed differences in their antimicrobial activity, which could not be explained satisfactorily.

These abnormalities could not be easily explained either by differences of antibiotic absorption or by different physiological responses of the human body, either by sex or by age, constitution, etc. It becomes necessary to consider a very representative factor common to the characteristics of previous treatments.

These observations lead us to think of the existence of antagonistic substances, not natural, but of a circumstantial origin in the host organism and capable of being formed as a response to an external stimulus promoted by the drug. 